\title{
Construindo um robô metareciclado: uma proposição de convergência entre robótica educacional e educação socioambiental
}

\author{
Ronilson dos Santos Bezerra ${ }^{1}$, Marlisson Oliveira de Almada ${ }^{2}$ \\ ${ }^{1}$ Universidade Federal do Oeste do Pará (UFOPA) \\ Santarém - Pa - Brasil \\ ${ }^{2}$ Universidade Federal de Mato Grosso (UFMT) \\ Cuiabá - Mt - Brasil \\ ronilson.bezerra@ufopa.edu.br, marlisson_almada@hotmail.com
}

\begin{abstract}
This article describes the creation of a prototype of an autonomous mobile robot, using metareciclados (electronic gadget parts) material, programmed on the Arduino platform. It aims to encourage building robots at low cost to use in the teaching/learning process, in order to promote social and environmental responsibility by using the educational robotic as tool.
\end{abstract}

Resumo. Este artigo descreve a criação de um protótipo de um robô autônomo móvel, utilizando componentes metareciclados e programado na plataforma Arduino. O mesmo objetiva incentivar a criação de robôs de baixo custo, para o uso no processo de ensino-aprendizagem, e promover a responsabilidade socioambiental ao mesmo tempo em que se utiliza a robótica educacional.

\section{Introdução}

Ao longo dos últimos anos, diferentes teóricos discutem a inserção das Tecnologias da Informação e da Comunicação (TICs) no processo educativo.

Para Almeida (2008), o maior desafio ainda é universalizar o acesso às TIC para atingir todo o contingente de alunos brasileiros, docentes e estabelecimentos escolares e ampliar a compreensão de que o alicerce conceitual para o uso de tecnologias na educação é a sua integração ao currículo, ao ensino e à aprendizagem ativa, numa ótica de transformação da escola e da sala de aula em um espaço de experiência, de formação de cidadãos e de vivência democrática, ampliado pelo seu uso.

É neste cenário desafiador que a robótica educacional, também conhecida como robótica pedagógica, vai encontrando seu espaço, mostrando-se capaz de integrar estas tecnologias ao conteúdo pedagógico de forma lúdica e interdisciplinar.

Para Schons et al. (2004) a robótica pedagógica "[...] constitui nova ferramenta que se encontra a disposição do professor, por meio da qual é possível demonstrar na prática muitos dos conceitos teóricos, às vezes de difícil compreensão, motivando tanto o professor como principalmente o aluno". Além disso, a robótica educacional é multidisciplinar, podendo ser utilizada como ferramenta pedagógica nas mais diversas áreas do conhecimento. 
Atualmente, existem diversos kits educacionais que podem auxiliar neste processo de introdução da robótica na educação (Silva, 2012). No entanto, apesar das vantagens e facilidades que estes kits apresentam, nem todas as escolas possuem recursos financeiros para adquiri-los. Mesmo quando estas conseguem adquirir, tanto o professor quanto o aluno podem ter interesse em possuir seus próprios kits, para realizar seus experimentos e/ou praticar em casa o que foi aprendido no ambiente escolar. Infelizmente, nem todos têm poder aquisitivo suficiente para isto.

Por outro lado, atualmente há uma grande quantidade de "lixo eletrônico" sendo descartado todos os dias. Na maioria das vezes este descarte é feito de forma errada, causando danos ao meio ambiente, uma vez que grande parte destes componentes "possuem metais pesados que podem causar diversas complicações para o meio ambiente e para a saúde do ser humano[...]" (Cerri, 2015). No entanto, sabe-se que grande parte deste "lixo eletrônico", na verdade não é lixo, mas sim uma importante fonte de matéria prima para quem deseja trabalhar com a metareciclagem, o que de acordo com Metarede (2014), é o meio mais seguro e consciente de reciclar o lixo eletrônico, e consiste na desconstrução do lixo tecnológico para a reconstrução da tecnologia.

Diante disso, este trabalho vem apresentar uma alternativa para criação de robôs de baixo custo, utilizando "lixo eletrônico", além de outros materiais reciclados. Para Foresti (2006), um robô é um dispositivo, ou grupo de dispositivos, eletromecânico ou biomecânico, capaz de realizar tarefas de maneira autônoma, pré-programada ou através de controle humano. Este trabalho apresenta um protótipo de um robô móvel autônomo, com habilidades e inteligência necessária para percorrer um caminho sem intervenção humana, sendo capaz de perceber e contornar os obstáculos que estejam em seu caminho.

\section{Trabalhos Relacionados}

A criação de dispositivos robóticos baseados em soluções livres e em sucatas como tecnologia de mediação para construção do conhecimento é denominada de Robótica Livre. Esta difere dos produtos (kits robóticos) comerciais, pois foca no uso de softwares livres (GNU, 2015) como base para a programação dos dispositivos e utilizase de sucatas de equipamentos para a construção de kits alternativos de robótica pedagógica (César, 2009). Silva (2012) aborda sobre uma comparação entre seis kits robóticos disponíveis no mercado e um kit de custo mais acessível, utilizando sucatas e programado na linguagem Arduino. De acordo com Neto et al. (2013), o uso da Robótica Educativa de baixo custo, utilizando sucatas, cumpre não apenas o seu papel educacional, mas também auxilia no descarte correto do lixo eletrônico.

Em seu trabalho, César (2009) faz uma abordagem profunda sobre a Robótica livre e apresenta alguns protótipos, programados com a linguagem Logo (ProjetoLogo, 2015). Por sua vez, Silva (2012), além do comparativo entre os kits, mostra a criação de um protótipo com o custo mais acessível, todavia, este ainda possui diversos componentes comprados, tais como placa Arduino Duemilanove (Arduino, 2015), matriz de contatos, caixa de redução e outros. Com isto, o robô ficou com um custo final de mais de duzentos reais. Já Neto et al. (2013) dar um enfoque maior no uso de componentes reciclados na robótica educativa. 
Apropriando-se deste conhecimento, abordado nos trabalhos supracitados, além de outras fontes bibliográficas pesquisadas, este trabalho vem propor o uso de robôs com componentes reciclados e utilizando uma plaquinha própria, montada a partir do Arduino standalone (Arduino, 2015) visando o menor custo possível. Além disto, apresenta um protótipo de um robô de baixo custo, com o passo a passo de sua criação para facilitar aos iniciantes no ensino/aprendizagem da robótica educacional.

\section{Montagem do protótipo}

Incialmente foi feito o levantamento e posterior aquisição do material necessário, a saber: madeira, disco rígido, motores de gravadoras de CD (Compact Disc), elástico, cabos de rede, canetas, tampas de latas e prancheta de acrílico. Além destes, vários componentes eletrônicos foram coletados em sucatas e apenas alguns, que não puderam ser reciclados, foram adquiridos em lojas on-line. Entre estes, estão: um sensor ultrassônico, dois sensores LDRs (do inglês Light Dependent Resistor) e um kit de Arduino standalone.

Logo após, foi criado um esquemático do projeto no software Fritzing (Fritzing, 2015), para validar as disposições das conexões dos componentes do robô. Após isto, a montagem foi iniciada, seguida da programação do código responsável pelo controle das funções do robô.

\subsection{O chassi}

Primeiramente foi utilizado um pedaço de madeira reciclada para confeccionar a base do chassi. Neste foram fixados: os motores retirados das gravadoras de CD e os suportes das rodas, feitos como motores de disco rígido (Figura 1a).

A lateral do robô foi confeccionada com pedaços de uma régua escolar e as bases (inferiores e superiores) foram feitas com pedaços de prancheta reciclada. Após a montagem, o chassi foi adesivado, para dar um melhor acabamento, conforme pode ser visto na figura $1 b$.

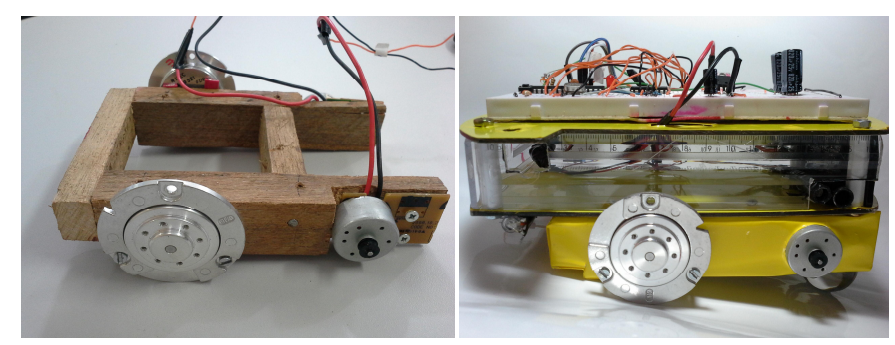

Figura 1. Chassi de madeira com os motores e suporte para as rodas (a) e o chassi adesivado e com sua lateral feito com régua (b)

\subsection{Os Motores de Corrente Contínua}

Os motores adotados neste projeto são motores DC, retirado de duas gravadoras de CD. Os motores de corrente contínua (CC) ou motores DC (Direct Current) como também são chamados, são dispositivos que operam aproveitando as forças de atração e repulsão geradas por eletroímãs e imãs permanentes (NCB, 2015). 
Este tipo de motor possui uma alta velocidade, mas fornece um torque muito baixo. Por este motivo, em geral, quando se utiliza este tipo de motor em robôs, necessita-se de uma caixa de redução, capaz de inverter esta relação de força versus velocidade.

Neste projeto, em vez de utilizar caixa de redução, preferiu-se utilizar uma polia pequena, acoplada ao eixo do motor DC, e uma polia grande, feita com uma tampa de lata, com praticamente o mesmo diâmetro do disco rígido. Esta foi acoplada à roda, conforme mostra a figura 2a. Para interligá-las, foram utilizadas borrachas amarelas, usadas para amarrar dinheiro, para atuarem como correias (Figura 2b).

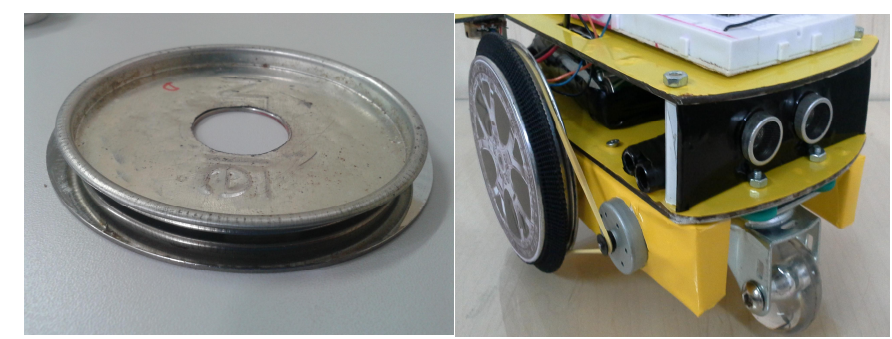

Figura 2. Polia feita de tampa de lata (a) e a correia de borracha interligando o motor às rodas traseiras (b)

\subsection{As Rodas}

Dois discos rígidos foram utilizados como rodas traseiras, sendo que suas bordas foram vestidas por um elástico para aumentar a aderência com o solo. Na parte interior dessas rodas foram fixadas as polias e na parte externa das mesmas, foram colocadas tampas de lata, adesivadas, funcionando como uma espécie de "calota" para melhorar a aparência das rodas (Figura 2b). Na parte dianteira do robô foi utilizada uma roda giratória, também chamada de roda louca, para dar sustentação ao robô, conforme pode ser visto na figura $2 b$.

\subsection{Placa Controladora}

Neste projeto, poderia ter sido utilizado uma placa controladora Arduino, no entanto, como este visa o baixo custo, a opção escolhida foi a aquisição de um kit Arduino standalone (Arduino, 2015), uma vez que uma placa Arduino Uno (um dos mais baratos), custa em média oitenta e cinco reais (Robocore, 2015), enquanto um kit standalone custa menos de quinze reais (Instituto Digital, 2015).

Arduino é uma plataforma de código aberto, projetado para computação física baseado em uma placa com entrada e saídas digitais e analógicas que através de seu microcontrolador permite a criação de modelos independentes ou controlados por meio de um computador (Arduino, 2015).

O kit standalone vem com todos os componentes necessários para montar uma placa, com o mesmo número de portas do Arduino Uno (quatorze digitais e seis analógicas), uma vez que ambos utilizam o mesmo microcontrolador, o Atmega328.

Inicialmente, o kit foi montado em uma matriz de contato (ou protoboard). Todavia, para deixar o projeto com uma aparência melhor, preferiu-se montá-lo em uma placa de papelão, utilizando o conceito do Paperduino (Paperduino, 2015). Para isto, foi 
realizada a prototipagem da placa e depois impressa em um papel glossy (Figura 3a). O papel foi colado sobre um papelão e a seguir o mesmo foi recortado e perfurado, para logo após receber os componentes conforme exibido nas figuras $3 \mathrm{~b}$ e $3 \mathrm{c}$.

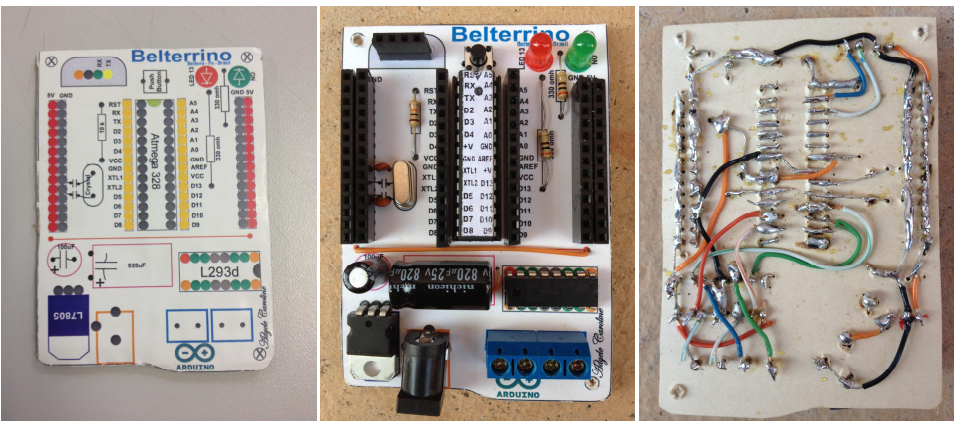

Figura 3. Layout da placa (a), placa em papelão (b) e o circuito feito com fios por baixo do papelão (c)

A placa feita no papelão atendia as necessidades deste projeto, todavia, devido à dificuldade para fixar os componentes, e, objetivando facilitar para as pessoas que quisessem confeccionar suas próprias, uma nova placa foi prototipada no software Fritzing (Fritzing, 2015). Neste foi gerado o layout da placa e a partir deste iniciou-se o processo de impressão da placa em um material próprio, chamado de fenolite.

Para isto, a impressão foi realizada por uma impressora a laser, em um papel de superfície lisa (semelhante ao papel glossy). A seguir, utilizando um ferro elétrico, a placa de fenolite foi aquecida por alguns segundos. Logo após, a face impressa do papel foi pressionada contra a superfície quente do fenolite, que continuou sendo aquecida por mais alguns segundos (Figura 4a). Após este procedimento, toda a tinta do papel foi transferida para placa e as pequenas falhas foram corrigidas com um pincel marcador de CD (Figura 4b). Logo após, a placa foi lançada dentro de uma solução de percloreto de ferro para corroer todo o cobre que não estava coberto pelo desenho do circuito impresso. Completada a corrosão, a placa foi perfurada para logo após receber os componentes (Figuras 4c e 4d).
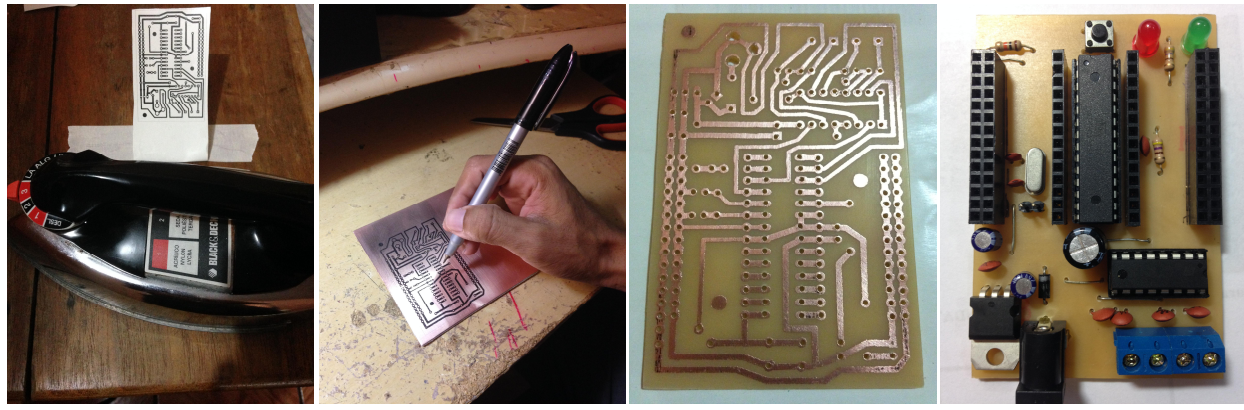

Figura 4. Processo de transferência térmica (a), corrigindo as imperfeições (b), fenolite após corrosão e perfuração (c) e a placa pronta (d)

\subsection{Ponte H}

Para acionar os motores DC a partir dos sinais das portas do Arduino, foi utilizado um circuito conhecido como ponte $\mathrm{H}$. Este circuito funciona como proteção ao microcontrolador Atmega328, uma vez que as portas digitais deste só fornecem até 40 
mA (Arduino, 2015) e os motores DC necessitam de muito mais corrente. A ponte $\mathrm{H}$ também funciona como inversor de corrente, uma vez que um motor DC muda o sentido de sua rotação, à medida que a corrente é invertida.

Uma ponte $\mathrm{H}$ pode ser construída utilizando-se chaves, relés ou transistores (NCB, 2015), porém, para deixar mais simples este projeto, foi utilizado um Circuito Integrado (CI) L293d. Este CI possui internamente duas pontes $\mathrm{H}$, podendo controlar motores de até $36 \mathrm{~V}$ de alimentação e suporta corrente de saída de $600 \mathrm{~mA}$ (NCB, 2015).

Para facilitar ainda mais, o CI L293d foi fixado na placa controladora. Desta forma, o usuário não precisará ter conhecimento do esquema de ligação dos motores ao CI, restando a este apenas ligar os motores nos bornes, conforme mostrado na figura 5. Para acionar estes motores, por meio da ponte $\mathrm{H}$, utilizam-se dois pares de portas digitais do Atmega328.

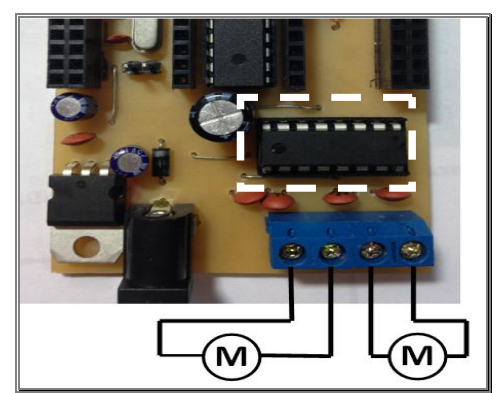

Figura 5. Ligação dos motores à ponte H. No detalhe tracejado, vê-se o CI L293d

\subsection{Sensores}

Para Secchi (2012) uma característica dos robôs móveis é o fato de possuírem algum sistema para evitar obstáculos. Neste projeto, foram utilizados dois tipos de sensores para auxiliar na detecção de obstáculos: um ultrassônico (modelo HC-SR04) na parte frontal do robô e dois sensores de luz nas laterais.

\subsubsection{Sensor Ultrassônico}

O sensor ultrassônico HC-SR04, mostrado na Figura 6a, é capaz de medir distâncias de 2 a $400 \mathrm{~cm}$, com ótima precisão (Filipeflop, 2015). Ele possui quatro pinos: Vcc (+5 volts), Gnd (Terra), Trigger (emissor) e Echo (receptor). Estes dois últimos, são conectados a duas portas digitais do Atmega328. A função deste sensor é detectar os obstáculos no ambiente, para auxiliar o robô na tomada de decisões.

Esta deteç̧ão é feita da seguinte forma: inicialmente é necessário alimentar o módulo e colocar o pino Trigger em nível alto por mais de 10 microssegundos (us), assim, o sensor emitirá uma onda sonora que ao encontrar um obstáculo rebaterá de volta em direção ao módulo, conforme ilustrado na figura $6 \mathrm{~b}$, sendo que neste tempo de emissão e recebimento do sinal, o pino Echo ficará em nível alto. Logo, o cálculo da distância pode ser feito de acordo com o tempo que o pino Echo permaneceu em nível alto após o pino Trigger ter sido colocado em nível alto. Portanto, para calcular a distância, basta multiplicar o "tempo Echo em nível alto" pela velocidade do som e dividir o resultado por dois (Filipeflop, 2015). 
Dessa forma, para encontrar a distância, têm-se a seguinte fórmula: $\mathrm{d}=\left(\mathrm{t}^{*} \mathrm{v}\right) / 2$. Onde: "d" é distância entre o sensor e o obstáculo; "v" é a velocidade que o som de propaga no ar $(340 \mathrm{~m} / \mathrm{s})$, e; "t" que é o tempo de resposta.

Para encontrar a distância em centímetro, utiliza-se a fórmula: $\mathrm{d}=\mathrm{t} / 58$. Para chegar a esta fórmula, deve-se considerar que a velocidade do som é igual a $340 \mathrm{~m} / \mathrm{s}$, o que equivale a $29,4 \mathrm{us} / \mathrm{cm}$.

Dessa forma tem-se que: $\mathrm{d}=\left(\mathrm{t}^{*} 1 / 29,4\right) / 2$. Fazendo as multiplicações, simplificações e arredondamentos, chega-se à fórmula $\mathrm{d}=\mathrm{t} / 58$.

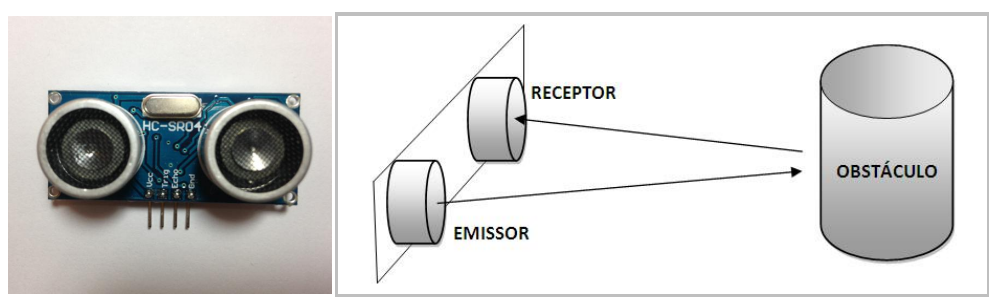

Figura 6. Sensor Ultrassônico HC-SR04 (a) e ilustração do funcionamento do Sensor Ultrassônico (b)

\subsubsection{Sensor de Luz}

O sensor de luz Light Dependent Resistor (LDR), mostrado na figura 7a, é um componente eletrônico cuja resistência diminui quando sobre ele incide energia luminosa. Por meio das portas analógicas do Atmega328, é possível detectar esta variação de luminosidade traduzida em números, que pode variar de 0 a 1023.

Este é um sensor de baixo custo, com preço de aproximadamente sessenta centavos de real (Robocore, 2015), sendo facilmente encontrado em eletrônicas ou lojas virtuais. Neste trabalho, foram utilizados dois LDRs afixados nas laterais do robô, próximo à parte frontal do mesmo (Figura $7 \mathrm{c}$ ).

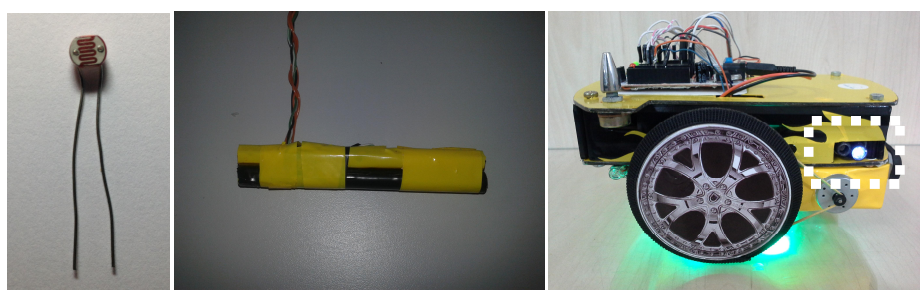

Figura 7. LDR (a), suporte para os LDRs (b) e o posicionamento dos LDRs no robô(c)

Para aumentar a eficiência desses sensores e diminuir a interferência da luz ambiente sobre os mesmos, foram utilizados dois pedaços de caneta como suporte para os sensores. Em um deles foram colocados os dois LDRs, um em cada extremidade, já com seus fios e resistores interligados e em seguida o cano foi isolado com fita preta, para evitar que alguma luminosidade indesejada interfira na leitura. Ao lado, foi colocado o outro cano de caneta, com dois LEDs (Light Emitting Diode) de alto brilho em seu interior, também nas duas extremidades, e isolados com fita preta e adesivo, conforme pode ser visto na figura $7 \mathrm{~b}$. Com isto, quando a lateral do robô se aproxima muito de um obstáculo, a luminosidade aumenta expressivamente, uma vez que a luz do LED incide sobre o mesmo, fazendo com que o LDR detecte um grande aumento de 
luminosidade, o que indicará a presença de obstáculo(s) e auxiliará o robô nas tomadas de decisões. A figura 8c mostra o posicionamento dos LDRs no robô.

\section{Programação e Testes}

Para implementar o código, foi utilizada a linguagem Arduino. Esta é uma DSL (Domain Specific Language - Linguagem de Domínio Específico) escrita em Java e desenvolvida tendo por base as linguagens Wiring e Processing (Arduino, 2015).

A programação foi realizada de maneira que ao ligar o robô, ele faz uma leitura através do seu sensor ultrassônico. Caso não haja obstáculo a menos de quarenta centímetros, ele se movimenta para frente. Durante o trajeto, ele faz leituras constantes dos valores obtidos pelo sensor ultrassônico e ao detectar obstáculos ele pára e analisa se há obstáculos em suas laterais, fazendo leituras por meio dos sensores LDRs. A partir destas leituras, ele consegue tomar uma decisão sobre seu direcionamento, podendo virar à esquerda ou à direita. Caso não seja possível virar para nenhum dos lados, o robô tentará sair para trás, sempre repetindo as leituras, até encontrar uma saída.

$\mathrm{Na}$ fase de testes, percebeu-se que havia alguns obstáculos que eram muito baixos, e por isto não podiam ser detectados pelo robô devido à diferença de altura, entre o sensor ultrassônico e o obstáculo. Para solucionar este problema, o robô foi programado para evitar engates. Isto foi feito armazenando as leituras do sensor ultrassônico em vetores e comparando-as constantemente, por meio de cálculos das médias e porcentagens. Sendo assim, por mais que o robô engate em algum objeto não detectado, ele foi programado para desengatar e seguir o seu percurso.

Durante os testes, também foram percebidos alguns problemas nas leituras do sensor ultrassônico que causavam instabilidade na navegação do robô. Tais problemas foram tratados dentro da programação com algumas técnicas, tais como: recursividade, para evitar que o sensor retornasse distância zero, além de fazer o robô repetir suas leituras várias vezes antes de tomar uma decisão, para certificar-se que não estava tomando uma decisão com base em um dado errado. Isto deu mais precisão ao robô e sanou praticamente a totalidade das falhas apresentadas pelo sensor ultrassônico.

Após as correções dessas falhas, os testes se mostraram promissores e o robô passou a detectar com muita exatidão os obstáculos à sua frente e tornou-se capaz de evitar qualquer engate, tendo uma boa autonomia e raramente necessitou da intervenção humana para desengatá-lo.

Para facilitar a compreensão da montagem e programação aqui apresentada, foi disponibilizado a prototipagem e o código completo deste robô, além de um vídeo mostrando o passo a passo da criação do protótipo. Isto pode ser visualizado no link: http://www.blogdoronilson.com/2014/07/construindo-um-robo-autonomo-com.html.

\section{Considerações finais e trabalhos futuros}

Com o desenvolver deste projeto pode-se concluir que a robótica pode tornar-se acessível, mesmo às escolas e/ou pessoas com baixo poder aquisitivo e que é possível construir robôs eficientes e com excelente qualidade e aparência fazendo o uso da metareciclagem. Portanto, este trabalho superou todas as expectativas e o custo final ficou muito abaixo do esperado. A tabela 1 mostra o comparativo de custo entre o 
protótipo de robô metareciclado mostrado neste trabalho e um robô sem metareciclagem, que também fora montado recentemente:

Tabela 1. Comparação de custo entre um robô com metareciclagem e outro com todos os seus componentes comprados

\begin{tabular}{|c|l|r|c|l|r|}
\hline \multicolumn{3}{|c|}{ ROBÔ METARECICLADO } & \multicolumn{3}{c|}{ ROBÔ SEM METARECICLAGEM } \\
\hline Quant. & \multicolumn{1}{|c|}{ Descrição } & Custo & Quant. & \multicolumn{1}{c|}{ Descrição } & Custo \\
\hline 1 & Chassi com rodas e motores* $^{*}$ & $\mathrm{R} \$ 0,00$ & 1 & Kit 4wd chassi robô & $\mathrm{R} \$ 155,00$ \\
\hline 1 & Placa criada com standalone $^{*}$ & $\mathrm{R} \$ 32,43$ & 1 & Arduino UNO & $\mathrm{R} \$ 85,00$ \\
\hline 1 & Sensor Ultrassônico & $\mathrm{R} \$ 13,99$ & 1 & Sensor Ultrassônico & $\mathrm{R} \$ 13,99$ \\
\hline 1 & Jumpers* & $\mathrm{R} \$ 0,00$ & 1 pct & Jumpers & $\mathrm{R} \$ 18,00$ \\
\hline 1 & Suporte 6 pilhas* & $\mathrm{R} \$ 2,00$ & 1 & Protoboard & $\mathrm{R} \$ 18,00$ \\
\hline 4 & Parafusos & $\mathrm{R} \$ 0,50$ & 1 & $\mathrm{Cl} 293 \mathrm{~d}$ & $\mathrm{R} \$ 10,50$ \\
\hline 1 & Roda Universal & $\mathrm{R} \$ 4,00$ & 4 & LEDs de alto brilho & $\mathrm{R} \$ 1,00$ \\
\hline 1 & Elástico* & $\mathrm{R} \$ 0,00$ & 4 & LEDs difuso & $\mathrm{R} \$ 0,12$ \\
\hline 1 & Adesivo & $\mathrm{R} \$ 8,00$ & 1 & Suporte 6 pilhas & $\mathrm{R} \$ 8,00$ \\
\hline 4 & LEDs de alto brilho * & $\mathrm{R} \$ 2,00$ & 1 & Servo motor & $\mathrm{R} \$ 13,90$ \\
\hline CUSTO TOTAL & $\mathbf{R} \$ \mathbf{6 2 , 9 2}$ & CUSTO TOTAL & $\mathrm{R} \$ \mathbf{3 2 3 , 5 1}$ \\
\hline * Componentes reciclados ou metareciclados total ou parcialmente & \\
\hline
\end{tabular}

É importante ressaltar que a ideia deste trabalho não era criar um modelo, como uma receita de bolo, e sim mostrar uma das possibilidades de robôs de baixo custo, e com isto, ajudar e incentivar os docentes e discentes que estão iniciando no processo de ensino/aprendizagem da robótica educacional.

O desafio agora é apropriar-se dos conceitos de robótica livre e metareciclagem, e a partir de então, criar robôs que possam ser utilizados dentro das escolas, de acordo com suas necessidades e recursos disponíveis. As escolas poderiam promover, por exemplo, competições de criação de robôs de baixo custo. Uma competição interessante seria criar robôs com o menor custo possível, ou com custo similar, mas com outras habilidades implementadas (seguidor de linha, reconhecimento de som ou cores e outros). As escolas também poderiam promover competições internas, no estilo das realizadas na Mostra Nacional de Robótica (MNR) e na Olimpíada Brasileira de Robótica (OBR), sendo que todos os robôs deveriam ser criados com material reciclado.

Como trabalhos futuros, pretende-se criar o chassi deste robô em uma versão para impressão em 3D, assim, quem não tiver madeiras ao alcance, ou não puder manuseá-las (no caso de crianças com pequena idade), poderá baixar o projeto e mandar imprimir o chassi. A ideia é deixar o projeto acessível para mais pessoas, sem que este perca a essência da metareciclagem e baixo custo, uma vez que os componentes eletrônicos metareciclados, continuarão sendo utilizados. Também seria importante a criação de um manual ou mesmo um website com tutoriais ensinando como/onde encontrar componentes para reciclar, como retirá-los, testá-los e etc. Assim, mesmo usuários sem nenhum conhecimento de eletrônica, criaria seu próprio robô com muita facilidade. Neste sentido, um website seria mais interessante, pois poderia ser alimentado por centenas de pessoas do mundo inteiro, cada um compartilhando seus conhecimentos e experiências. 


\section{Referências}

Almeida, M.E.B. (2008) "Tecnologias na Educação: dos caminhos trilhados aos atuais desafios”. Boletim de Educação Matemática, vol. 21, núm. 29, 2008, pp. 99-129. Rio Claro, SP.

Arduino (2015), http://www.arduino.cc, Março.

Paperduino (2015), http://paperduino.eu, Março.

Cerri, A. (2015) "Mercúrio, cádmio e chumbo: os inimigos íntimos presentes nos eletrônicos", http://goo.gl/FHi4pI, Março.

César. D. R. (2009) "Potencialidades e limites da robótica pedagógica livre no processo de (re)construção de conceitos científico-tecnológicos a partir do desenvolvimento de artefatos robóticos", Dissertação de Mestrado, Universidade Federal da Bahia, Salvador, BA.

Filipeflop (2015), http://filipeflop.com, Março.

Foresti, H. B. (2006) "Desenvolvimento de um robô bípede autônomo", Dissertação de Mestrado, Universidade Federal de Pernambuco, Recife, PE.

Fritzing (2015), http://fritzing.org, Março.

GNU (2015) “O que é software livre?”, http://www.gnu.org/philosophy/free-sw.ptbr.html, Março.

Instituto Digital (2015), http://www.institutodigital.com.br, Março.

MetaRede (2015), http://www.metarede.org, Março.

ProjetoLogo (2015), http://projetologo.webs.com/texto1.html, Março.

Robocore (2015), http://www.robocore.net, Março.

Schons, C., Primaz, E e Wirth, G. A. P. (2004) "Introdução a Robótica Educativa na Instituição Escolar para alunos do Ensino Fundamental da disciplina de Língua Espanhola através das Novas Tecnologias de Aprendizagem". Anais do I Workshop de Computação da Região Sul.

Secchi, H. A. (2012) "Uma Introdução aos Robôs Móveis”, Traduzido por Almeida, C. H e Martins, N. F, Universidade Nacional de San Juan - UNSJ - Argentina.

Silva, F. I. (2012) "Análise de kits de Robótica Educacional e Elaboração de um kit Protótipo de Custo Acessível Baseado na Plataforma Arduino", Universidade Estadual da Paraíba - UEPB.

NCB (2015), http://www.newtoncbraga.com.br, Março.

Neto, R. S., et al. (2013) "Robótica Educativa de Baixo Custo - Uma Proposta de Trabalho para O Projeto de Extensão Museu da Computação da UEPG”, http://www.aeapg.org.br/8eetcg/anais/60105_vf1.pdf, Março. 